\title{
Assessment of Fatigue Behavior and Effects of Crack Growth in Aluminium Alloys 6082 under Various Stress Ratios
}

\author{
Walid Roundi", Abdellah Elgharad ${ }^{\#}$ \\ \# Department of Mechanical Engineering, Moroccan Laboratory of Innovation and Industrial Performance (LaMIPI), \\ Higher School of Technical Education of Rabat, (ENSET), Mohammed V University in Rabat, Morocco. \\ E-mail: Roundi.walid@gmail.com
}

\begin{abstract}
The purpose of this study is to investigate the fatigue behaviour of the aluminium alloy 6082 by a finite element analysis (FEA). The tests are released for various specimens subjected to cyclic tensile loading in order to characterize the damage evolution and the fatigue strength of the aluminium alloy 6082. The results show the Wöhler curves (S-N curves) for the tested specimens under various stress amplitude levels and for different stress ratios values $(R=0, R=0.5, R=-1)$. The obtained data highlights the strong influences of the stress ratios $R$ and the effects of high cyclic loading on the decreasing of aluminium alloys 6082 life and performances. Afterward, fatigue crack growth under tensile loading was investigated, in this way fatigue tests have been performed on specimens with different pre-cracks sizes to underline the influences of the crack growth on the lifetime and fatigue behaviour of the tested specimens. The predicted fatigue life and the results obtained for the different loading conditions presented in this study were found to be in good agreement with the experimental fatigue investigations published in the literature
\end{abstract}

Keywords - Fatigue; Aluminium alloy; S-N curve; FEA, Specimen; Stress ratios

\section{INTRODUCTION}

The application of aluminium alloys in many mechanical components has been increasingly employed especially in automotive, rail vehicles and aeronautical industry, due to their good mechanical properties and low specific weight, also is related to recycling, as all kinds of aluminium alloys can be reused in different products. Aluminium alloy has a density around one third that of steel (around $2700 \mathrm{~kg} / \mathrm{m} 3$ ), and it is often used advantageously in applications where low weight and high strength are required. We can find two main classes of aluminium alloys: Cast alloys and Wrought. The increasing use of aluminium alloys in various fields and for high performance products in severe environments requires the complete understanding and knowing of their properties to ensure the best performances and avoid defects, micro-structural features, and any type of damage.

Among all these factors which could fail structures in different modes, fatigue can be the principal cause in the presence of defects and reducing the life of any components. The fatigue can produce larger strain deformation, crack initiation and growth, which can lead to the rupture and the destroying of structures. Wang et al [1] have studied the fatigue and fracture behaviour of structural Al-alloys up to very long life regimes, during cyclic tests they observed a significant interfacial voids were in the Al-alloys during crack initiation and early fatigue crack growth process. Suresh [2] shows that the fatigue crack growth is typically governed by the crack tip stress intensity. Many Studies have been conducted on the fatigue and deformation behavior of aluminum alloys with different heat treatments (over, under and peak aged), and specifically the interactions between dislocations, slip band structures and precipitates [3-8].

Other studies have been carried out on the influences of microstructure and micro-porosity on the mechanical properties of aluminium cast alloys [9-11]. The fatigue crack propagation can be separated into three stages [12-14]. Stage I crack growth is usually limited to within a single grain and is generally characterized by crack propagation through shear decohesion on a single slip system. The crack will transition to Stage II type growth at higher stress intensities where two slip systems will be active and multiple grains will be located within the crack tip plastic zone. Stage II crack growth is characterized by crack growth normal to the loading direction and the formation of fatigue striations on the fracture surface. The final step in the fatigue process is overload fracture (Stage III crack propagation), which leads to the complete failure of the material.

In that reason, the present study deals with the fatigue damage progression, the effects of high cyclic loading and crack growth on the decreasing of the mechanical properties of aluminium alloy (6082). 
Static and cyclic tensile tests have been performed, first on normal specimens and after on pre-cracked specimens to identify the influences of crack initiation and growth on the fatigue life of aluminium alloy (6082). The Results of the S$\mathrm{N}$ curves for the different loading conditions and under the various stress ratios values are presented in this study.

\section{FEA PROCEDURES}

During FEA an aluminium alloy (6082) is used and its mechanical properties and chemical composition are presented in Table I and Table II. The main characteristics of this alloy are good mechanical strength, high resistance to corrosion, thermal treatability and weldability.

TABLE I

CHEMICAL COMPOSITION OF THE USED ALUMINIUM ALLOY 6082

\begin{tabular}{|c|r|}
\hline \multicolumn{2}{|c|}{ Chemical Composition } \\
\hline $\mathbf{A l}$ & $96,41 \%$ \\
\hline $\mathbf{C r}$ & $0,23 \%$ \\
\hline $\mathbf{C u}$ & $0,08 \%$ \\
\hline $\mathbf{F e}$ & $0,4 \%$ \\
\hline $\mathbf{M g}$ & $0,8 \%$ \\
\hline $\mathbf{S i}$ & $0,9 \%$ \\
\hline $\mathbf{T i}$ & $0,08 \%$ \\
\hline $\mathbf{Z n}$ & $0,17 \%$ \\
\hline $\mathbf{M n}$ & $0,8 \%$ \\
\hline Others & $0,13 \%$ \\
\hline
\end{tabular}

TABLE II

MECHANICAL PROPERTIES OF THE USED ALUMINIUM ALLOY 6082

\begin{tabular}{|c|r|}
\hline \multicolumn{2}{|c|}{ Mechanical Properties } \\
\hline Density & $2,71 \mathrm{~g} / \mathrm{cm}^{3}$ \\
\hline Young's Modulus & $71 \mathrm{GPa}$ \\
\hline Yield Strength & $280 \mathrm{MPa}$ \\
\hline Ultimate tensile strength & $310 \mathrm{MPa}$ \\
\hline Thermal Expansion & $23.1 \mu \mathrm{m} / \mathrm{m}-\mathrm{K}$. \\
\hline
\end{tabular}

The tests were performed on cylindrical specimens that had a gauge diameter of $10 \mathrm{~mm}$ and a gauge length of 50 $\mathrm{mm}$ as shown in figure 1 . The specimens for static and fatigue tests have been axially loaded on one side and fixed in the other.

The following fatigue parameters were employed during cyclic tests: sinusoidal load cycles with constant amplitude (Fig 2), test frequency of $10 \mathrm{~Hz}$, three stress ratios $(\mathrm{R} 1=-1$; $\mathrm{R} 2=0 ; \mathrm{R} 3=0.5)$, and under an ambient temperature.

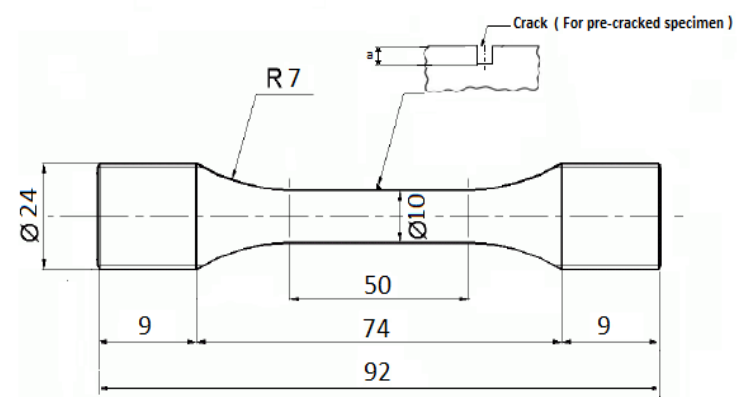

Fig 1 Specimens dimensions

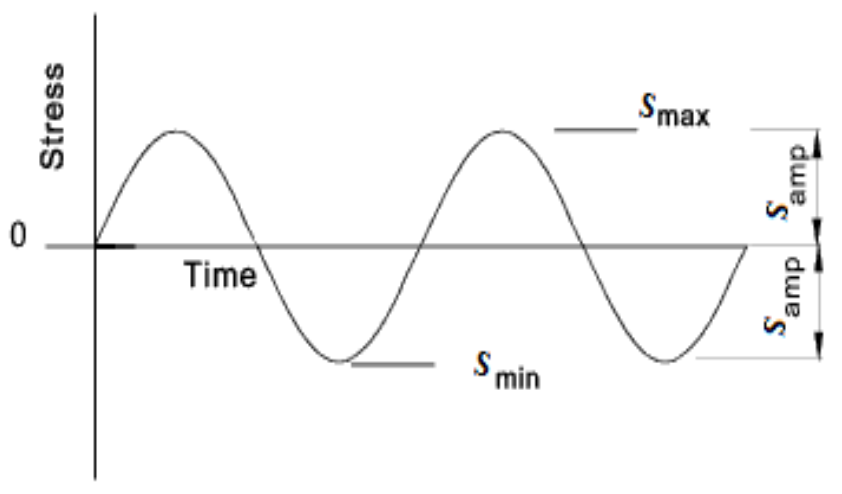

Fig 2..Applied Loading

The finite element analysis was realized using a technique known as Rainflow counting [16-18]. This technique is used in the fatigue analysis by converting the random loading to simple cycles. Algorithm of this method was developed by Endo and Matsuishi [19] and it's allows the application of Miner's rule and strain-life approach to compute fatigue damage on each cycle (Fig 3).

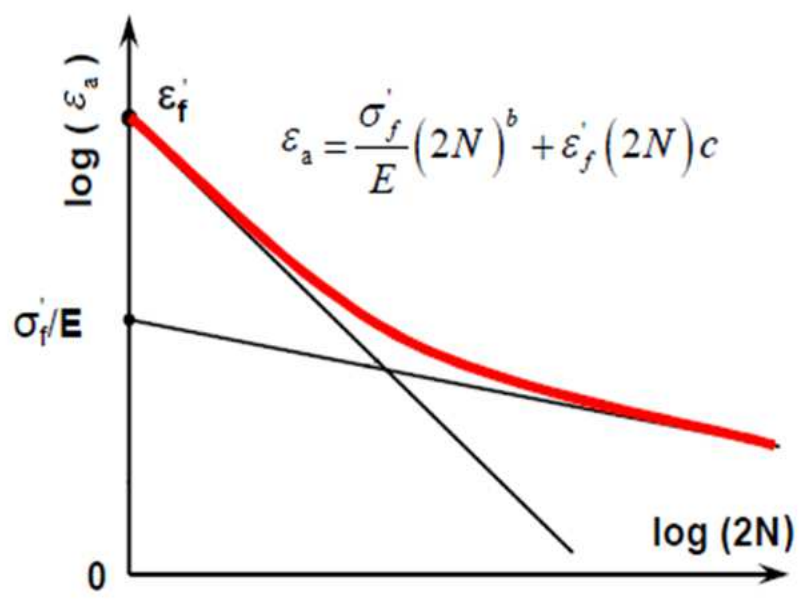

Fig.3. Strain-Life approach [20]

The strain-based approach is a comprehensive approach which can be applied to both low cycle and high cycle fatigue regimes. For long life applications where the plastic strain term is negligible, the total strain-life equation reduces to Basquin's formula which was also used for the stress-life $(\mathrm{S}-\mathrm{N})$ approach. The equation relating total strain amplitude $\mathcal{E}_{a}$ and life (N) is as follows (Eq 1):

$$
\varepsilon_{a}=\frac{\sigma_{f}^{\prime}}{E}(2 N)^{b}+\varepsilon_{f}^{\prime}(2 N)
$$

Where:

- $\sigma_{f}^{\prime}$ is the "Strength Coefficient", $E$ is the Young's Modulus

- b is the "Strength Exponent"

- $\varepsilon$ ' is the "Ductility Coefficient"

- $\mathrm{c}$ is the "Ductility Exponent" 
Figure 4 present the basic workflow used during the finite element analysis. The simulation process flows from left to right across the schematic. This configuration is analogous with the normal workflow of a typical finite element (FE) based simulation (pre-processing, followed by solving, followed by post-processing). For the 5-box trick, the three boxes on the left (FE Input, Material Mapping, and Load Mapping) entail pre-processing activities, the center box (CAE Fatigue Analysis) entails solving actions, and the box on the right (Fatigue Results Display) entails post-processing activities.

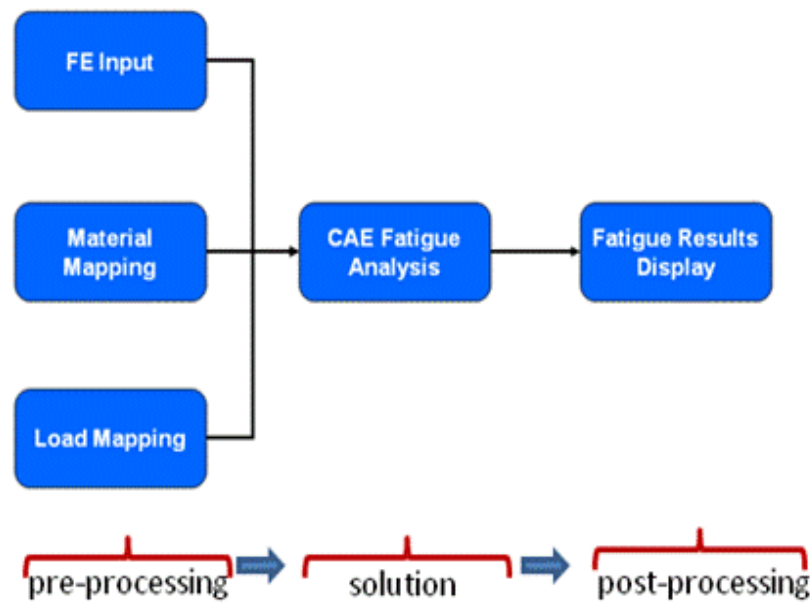

Fig 4 Workflow used during the FEA

The fatigue tests were carried out until total failure of the specimens. The results lead us to determine the $\mathrm{S}-\mathrm{N}$ curves under the various stress ratios values, the endurance limit and the influences of the crack growth in the fatigue life of the pre-cracked specimens.

Afterwards, it is possible to verify the Basquin relation (Eq 2) that can be used to adequately fit the obtained data correlating alternating stresses and number of cycles to failure, as expressed in Eq. 1.

$$
S a=A \times N^{i}
$$

Where $\mathrm{Sa}$ is the applied stress, $\mathrm{A}$ and $\mathrm{b}$ are respectively the constant and the curve exponent and $\mathrm{N}$ is number of cycles.

\section{RESULTS AND DISCUSSION}

\section{A. Static Tests}

The proposed results in Fig.5 depict the typical tensile stress versus strain curves obtained under static loading. It's observed that in the elastic region stress is linearly proportional to strain. When the load exceeds a value corresponding to the yield strength, the specimen undergoes gross plastic deformation. We can notice that the ultimate strength is equal to $310 \mathrm{Mpa}$ and the elastic limit is equal to 283Mpa.

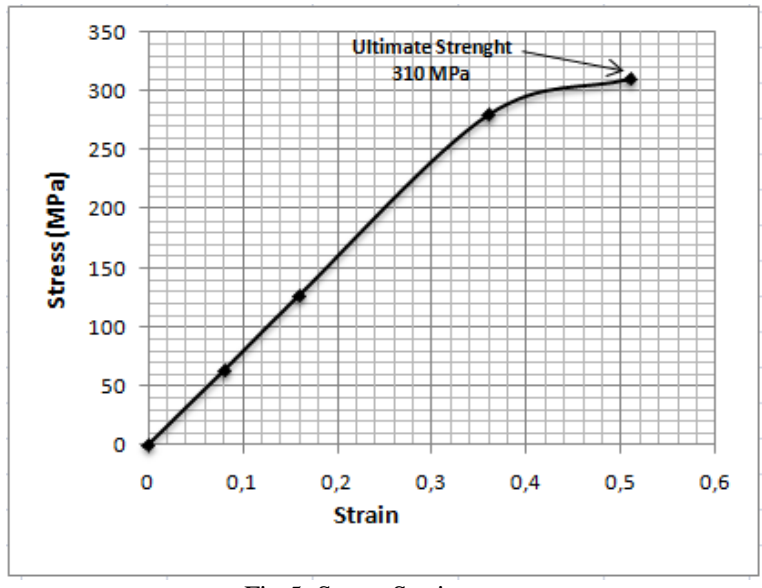

Fig 5 Stress-Strain curve

\section{B. Fatigue Tests}

During the past decades a number of models has been developed to study the fatigue behavior of materials. The most well know fatigue model is $\mathrm{S}-\mathrm{N}$ curve, which was originally developed for metallic materials. Figure 6 displays the $\mathrm{S}-\mathrm{N}$ curve for specimens under $\mathrm{R}=-1$.

Three fatigue life behaviors namely low-cycle, high-cycle and infinite life can be distinguished. Low-cycle regime extends up to $16.10^{3}$ cycles with the corresponding fatigue strength at $190 \mathrm{MPa}$, and the higher cycle life starts at $5.10^{6}$ cycles. Depending on the amount of applied stress the degree and rate of damage varied consequently. A greater stress level causes more damage than that of low stress level.

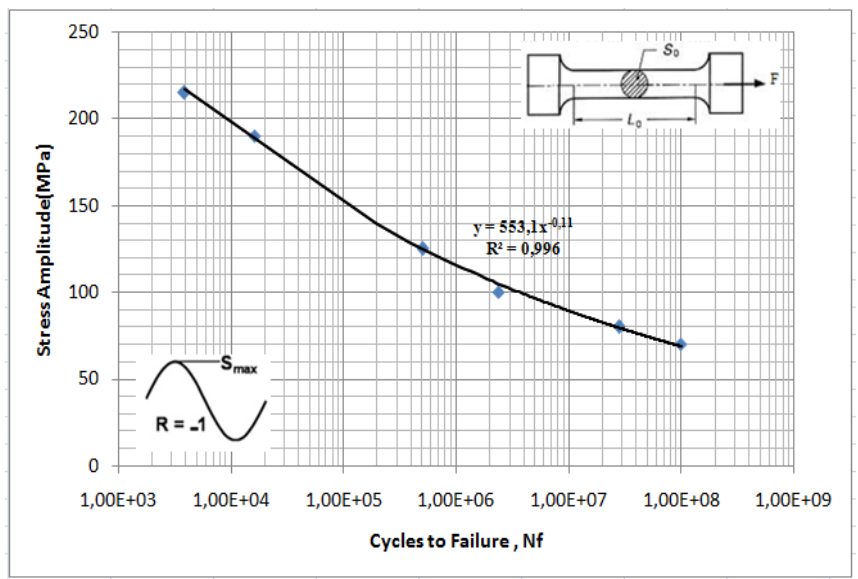

Fig 6. $\mathrm{S}-\mathrm{N}$ curve under $\mathrm{R}=-1$

Comparison of the fatigue behaviour of the specimens under the three stress ratios levels is presented in figure 7. The obtained fatigue results for the tested specimens under considered three stress ratios are shown in Table .2 .

It is observed that as the applied bending stress is increased, the life cycle of the specimen is decreased for all stress ratios values. The fatigue strength increase with $\mathrm{R}$ values and the fatigue life decrease significantly as the stress ratio was lowered. 


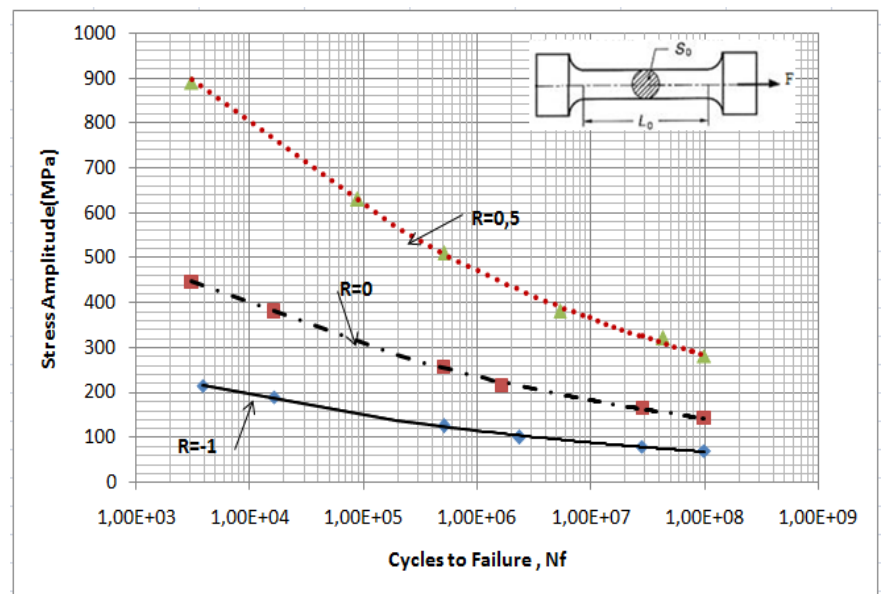

Fig 7 Comparison of the $\mathrm{S}-\mathrm{N}$ curves under the three stress ratio

TABLE III

FATIGUe Results For THE VARIOUS StRESS RATIOS

\begin{tabular}{|r|r|r|r|r|r|}
\hline \multicolumn{2}{|c|}{$\mathbf{R}=\mathbf{- 1}$} & \multicolumn{2}{|c|}{$\mathbf{R}=\mathbf{0}$} & \multicolumn{2}{c|}{$\mathbf{R}=\mathbf{0 , 5}$} \\
\hline $\mathbf{S}_{\mathbf{a}}$ & $\mathbf{N f}$ & $\mathbf{S}_{\mathbf{a}}$ & $\mathbf{N f}$ & $\mathbf{S}_{\mathbf{a}}$ & \multicolumn{1}{c|}{$\mathbf{f f}$} \\
\hline 215 & 3882 & 445 & $3,09 \mathrm{E}+03$ & 890 & 3087 \\
\hline 190 & 16287 & 380 & $1,63 \mathrm{E}+04$ & 630 & 89142 \\
\hline 125 & $5,10 \mathrm{E}+05$ & 255 & $5,13 \mathrm{E}+05$ & 510 & $5,13 \mathrm{E}+05$ \\
\hline 100 & $2,38 \mathrm{E}+06$ & 215 & $1,67 \mathrm{E}+06$ & 380 & $5,42 \mathrm{E}+06$ \\
\hline 89 & $2,80 \mathrm{E}+07$ & 165 & $2,87 \mathrm{E}+07$ & 320 & $4,35 \mathrm{E}+07$ \\
\hline 70 & $1,00 \mathrm{E}+08$ & 143 & $1,00 \mathrm{E}+08$ & 280 & $1,00 \mathrm{E}+08$ \\
\hline
\end{tabular}

When all predictions of S-N curves are rearranged into the form of Basquin's formula, the equations that best describe the obtained results can be represented by:

$$
\begin{array}{lll}
\text { - } & \text { For }(\mathrm{R}=-1): & 5 a=553,1 \times N^{-0,11} \\
\text { - } & \text { For }(\mathrm{R}=0): & \mathrm{Sa}=1087 \times N^{-011} \\
\text { - } & \text { For }(\mathrm{R}=0,5): & \mathrm{Sa}=2188 \times N^{-011}
\end{array}
$$

Figures 8 and 9 present and compare the (S-N) curves for normal and pre-cracked specimens under a maximal stress equal to $80 \mathrm{Mpa}$. It's observed that the pre-cracked specimens have a very low fatigue life and an accelerate damage evolution due to the crack growth.

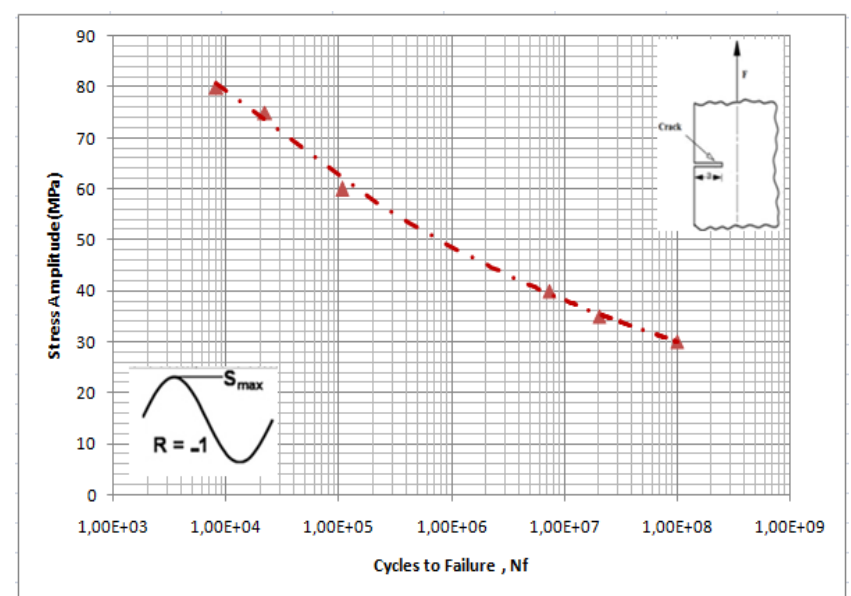

Fig 8 S-N curve for the pre-cracked specimen (crack length (a) $=3 \mathrm{~mm}$ and $\mathrm{R}=-1$ )

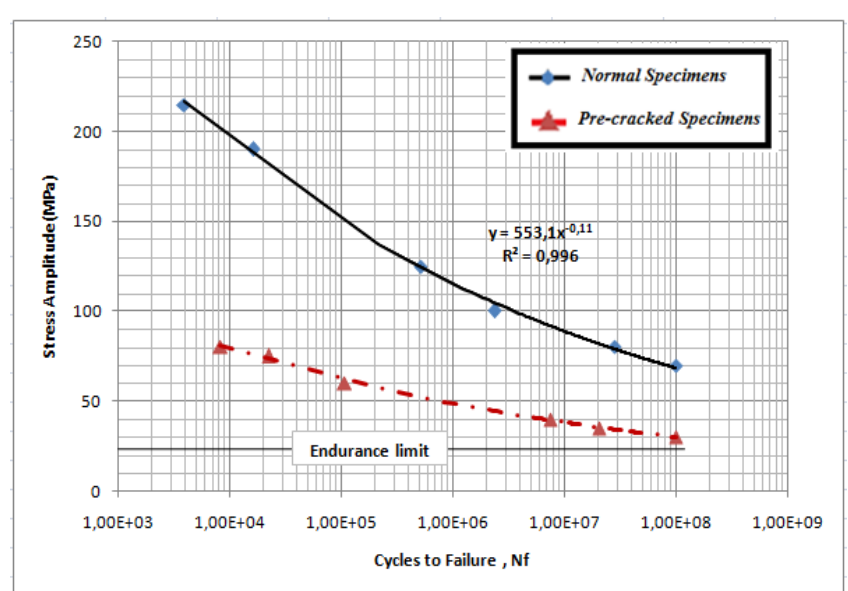

Fig 9 Comparison of S-N curves for the pre-cracked and normal specimen $(\mathrm{R}=-1, \mathrm{a}=3 \mathrm{~mm})$

The obtained effective endurance limit defined as the stress that causes failure at $10^{8}$ cycles, is equal to $30 \mathrm{MPa}$ for pre-cracked specimens and about $70 \mathrm{MPa}$ for normal specimens under $(\mathrm{R}=-1)$. The results show how the crack growth and fatigue damage can modify the mechanical properties of the tested material.

Figure 10 presents the fatigue behaviour of four different pre-cracked specimens with various initial crack sizes. It's observed that the number of cycles to failure decreases when the crack length increases. For instance, when the crack length (a) is equal to $3 \mathrm{~mm}$, the number of cycles to failure is about 1728 cycles, and with a pre-crack length equal to 2 $\mathrm{mm}$, the number of cycles to failure is equal to 2896 cycles.

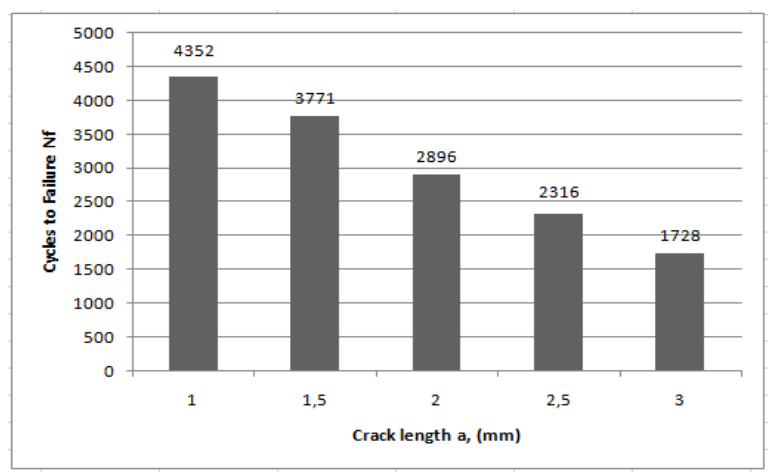

Fig 10.Crack length vs cycles to failure for different crack size

Figure 11 presents the result of the fatigue life of the precracked specimen under an applied stress equal to $80 \mathrm{MPa}$ and a stress ratio equal to -1 , the figure shows the cracked area that is most affected by fatigue (fatigue life about 8200 cycles), as well as the blue areas in which we have a more important lifespan. 


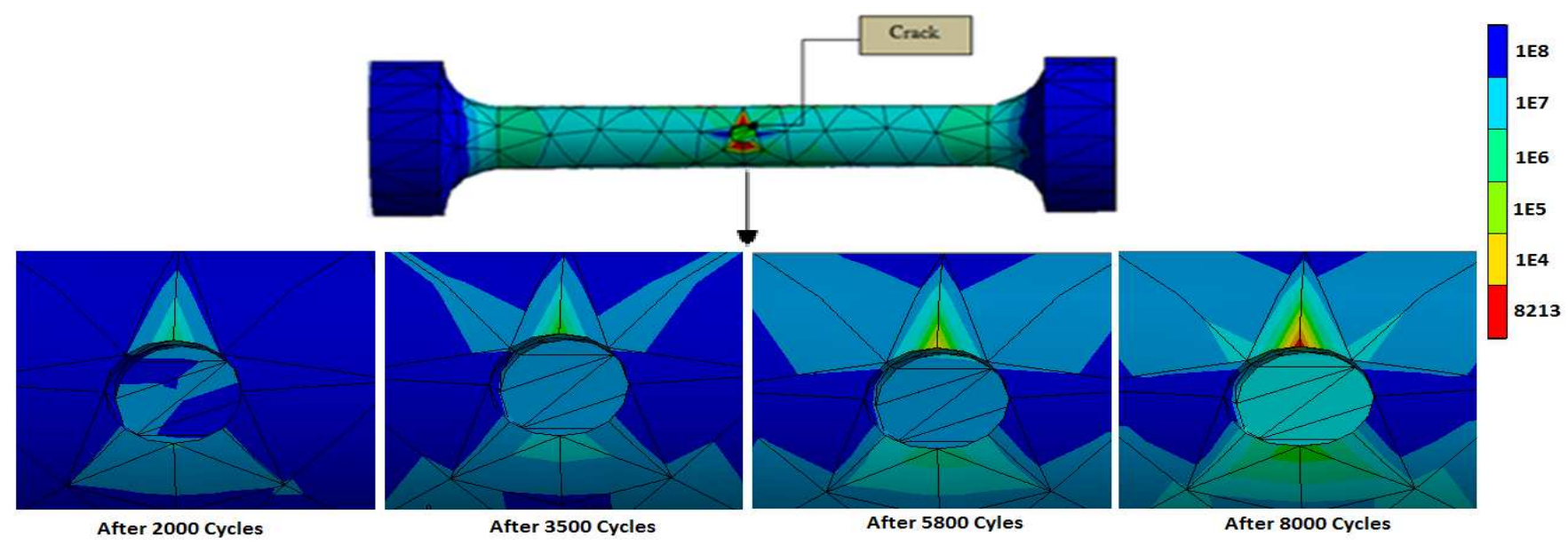

Figure 11 Fatigue behaviour of the cracked area during cyclic tests

\section{CONCLUSIONS}

The fatigue behaviour and the influences of damage evolution and crack growth on the decreasing of aluminium alloys (6082) performance have been investigated. When the fatigue load level increases, the fatigue life decreases. Conversely, at low fatigue load level, the fatigue life is long and the damage evolution occurs slowly. The great danger that can be assigned to all structures due to fatigue and cracking can be noticed. This study was also carried out by a finite element analysis of the fatigue response of aluminium alloy 6082 under different stress ratios. Results demonstrate that the fatigue strength increase with $R$ values. However, fatigue life decreases significantly as the stress ratio was lowered.

\section{NOMENCLATURE}

a Crack length

$\mathrm{mm}$

$\mathrm{N} \quad$ Number of cycles

$\mathrm{N}_{\mathrm{f}} \quad$ Number of cycles to failure

$\mathrm{R} \quad$ Stress ratio $\left(\mathrm{R}=\frac{\text { Snax }}{\text { 3nin }}\right)$

$\mathrm{S}_{\mathrm{a}} \quad$ Stress amplitude

$\mathrm{MPa}$

\section{REFERENCES}

[1] Q.Y.Wang, N.Kawagoishi, Q.Chen. Fatigue and fracture behaviour of structural Al-alloys up to very long life regimes. International Journal of Fatigue 2006, 28, pp 1572-1576.

[2] Suresh S. Fatigue of materials. New York, NY: Cambridge University Press, 1991.

[3] T. Hanlon. Fatigue Behavior of Nonocrystalline Metals and alloys". International Journal of Fatigue, 2005, 27, pp. 1147 - 1158.

[4] Ciavarella, M., \& Meneghetti. On fatigue limit in the presence of notches: classical vs.recent unified formulations. International Journal of Fatigue, 2004, 3, pp 289-298.

[5] Busby AK, Edwards L, Martin JW. Effect of aging and dispersoid content on tensile properties of $\mathrm{Al}-0.6 \mathrm{Mg}-1 \mathrm{Si}$ alloys. Materials Science and Technology, 1986, 4, pp 363-367.

[6] Bamberger, Minkoff. Some observations on dendritic arm spacing in $\mathrm{Al}-\mathrm{Si}-\mathrm{Mg}$ and $\mathrm{Al}-\mathrm{Cu}$ alloy chill castings. Journal of Materials Science,, 2010, 21, p.2781-2786.

[7] Jiang DM, Hong BD, Lei TC, Downham DA, Lorimer GW. Influence of aging condition on tensile and fatigue fracture behaviour of aluminium alloy 6063. Materials Science and Technology, 1991, 11, pp 1010-1014.
[8] M. Rosso, E. Romano. Study of fatigue properties of aluminium alloys produced by means of different casting processes. Matehn'02 - 3rd International Conference on Materials and Manufacturing Technologies, Cluj-Napoca, Romania, September 12-14, 2002.

[9] Taylor, D. Modelling of fatigue crack growth at the microstructural level. ComputationalMaterials Science, 2002, 25,pp 228-236.

[10] J-Y. Buffière, S. Savelli, P.H. Jouneau, E. Maire, R. Fougères. Experimental study of porosity and its relation to fatigue mechanisms of model Al-Si7-Mg0.3 cast Al alloys. Materials Science and Engineering, 2001, 316, p.115-126.

[11] Hayat, N., Toda, H., Kobayashi, T. et Wade, N. Experimental investigations of fatigue characteristics of $\mathrm{AC} 4 \mathrm{CH}$ cast aluminum alloys fabricated through rheocast and squeeze cast methods. Materials Science Forum, 2002, 396-402,pp 1353-1358.

[12] Ishihara, S, McEvily. Analysis of short fatigue crack growth in cast aluminum alloys. International Journal of Fatigue, 2002, 24, pp 11691174.

[13] D.C. Seo, J.J. Lee, and H.R. Daghyani. Fatigue crack growth behaviour of cracked aluminium plate repaired with composite patch. Composite Structures, 2003, 57, pp 323-330.

[14] V. Sabelkin, S. Mall, M.A. Hansen, R.M. Vanderwaker, and M. Derriso. Investigation into cracked aluminium plate repaired with bonded composite patch. Composite Structures, 2007, 79, pp 55-66.

[15] Savellis., Buffiere j.y., Fougeres R.. Pore characterization in a model cast aluminium alloy and its quantitative relation to fatigue life studied by synchrotron Xray microtomography. International Conference on Aluminium Alloys, Charlottesville, Virginia USA. Mater. Sci. Forum, 2000, 331, pp 197-202.

[16] Dowling, N. E. Mechanical behavior of materials : engineering methods for deformation, fracture, and fatigue (3 éd.). Upper Saddle River, N.J.: Pearson Prentice Hall, 2007.

[17] Michel O, Zakoua G. Rainflow. fatigue analysis for loads with multimodal power spectral densities. Marine Structures, 2008, 21, p.160-176.

[18] Gabriel M. Review and application of Rainflow residue processing techniques for accurate fatigue damage estimation. Int $\mathbf{J}$ Fatigue 2016, 82, p.757-765.

[19] Matsuishi M, Endo T. Fatigue of metals subjected to varying stress. Japan Society of Mechanical Engineers, 1968, p.37-40.

[20] Martin J.F. Cyclic Stress-Strain behavior and fatigue resistance of two structural steels. Fracture control program report no.9. University of illinois at urbana-champaign, 1973.

[21] Saravanan A, Scott F. Test method for corrosion pit-to-fatigue crack transition from a corner of hole in 7075-T651 aluminum alloy. International Journal of Fatigue, 2016, 91,pp 50-58.

[22] Fudong Li, Zhiyi Liu, Wenting Wu, Qi Zhao, Yaru Zhou. Slip band formation in plastic deformation zone at crack tip in fatigue stage II of 2xxx aluminum alloys. International Journal of Fatigue, 2016, 91, pp 68-78. 
[23] Jose I., Daniel C . Onset Frequency of Fatigue Effects in Pure Aluminum and 7075 (AlZnMg) and 2024 (AlCuMg) Alloys. metals, 2015, 6(3), 50 .

[24] Joyce,M.R.,Starink,M.J.Sinclair. Assessment of mixed mode loading on macroscopic fatigue crack paths in thick section $\mathrm{Al}-\mathrm{Cu}-\mathrm{Li}$ alloy plate. Materials \& Design, 2015, 93, pp 379-387.

[25] Lala Amarnath, Antara Bhattacharjee and K. Dutta. Ratcheting fatigue behaviour of Al-7075 T6 alloy: Influence of stress parameters. Materials Science and Engineering, 2016, 115, pp 1-8.

[26] M. Cieśla, G. Junak , A. Marek. Fatigue Characteristics of Selected Light Metal Alloys. Archives of Metallurgy and Materials, 2016, 61, pp 271-274.
[27] Yang, H.-H, Wang, Y.-L., Wang, X.-S., Pan, P, Jia, D.-W. Synergistic effect of environmental media and stress on the fatigue fracture behaviour of aluminium alloys. Fatigue Fract Engng Mater Struct, 2016,00, pp 1-8.

[28] Evren, T.; and Bilgehan, O. Influence of heat treatment on the mechanical properties of AA6066 alloy. Turkish Journal of Engineering and Environmental Sciences, 2007, 31, pp 53-60.

[29] Snchez-Santana, U.; Rubio-Gonzlez, C.; Mesmacque, G.; and Amrouche, A. Effect of fatigue damage on the dynamic tensile behavior of 6061-T6, 2009, 31, pp 1928-1937.

[30] Yahya, M.M. (2009). Low cycle fatigue failure of medium strength aluminum alloy 7020 at different heat treatment. Ph.D. Thesis. University of Baghdad, 2-47. 